\title{
Methyl jasmonate treatment increases podophyllotoxin production in Podophyllum hexandrum roots under glasshouse conditions
}

\author{
Christel L. C. Seegers • Rita Setroikromo • Pieter G. Tepper • \\ Peter Horvatovich • Ron Peters • Wim J. Quax
}

Received: 29 November 2016/Accepted: 30 March 2017 /Published online: 4 April 2017

(C) The Author(s) 2017. This article is published with open access at Springerlink.com

\begin{abstract}
Background and aim The endangered Podophyllum hexandrum is an important industrial source of podophyllotoxin, which is a precursor for the anticancer drugs etoposide and teniposide. Attempts to obtain podophyllotoxin through cell cultures or chemical synthesis have still a long way to go before being economical feasible. The objective of this study was to increase the root formation and podophyllotoxin production of $P$. hexandrum cultivated in a glasshouse.

Methods Root formation and podophyllotoxin production of $P$. hexandrum in sand or peat-perlite soil at $15^{\circ} \mathrm{C}$ or $25^{\circ} \mathrm{C}$ was determined. Furthermore, the influence of
\end{abstract}

Responsible Editor: Hans Lambers.

Electronic supplementary material The online version of this article (doi:10.1007/s11104-017-3245-6) contains supplementary material, which is available to authorized users.

C. L. C. Seegers · R. Setroikromo · P. G. Tepper •

W. J. Quax $(\bowtie)$

Department of Chemical and Pharmaceutical Biology, Groningen Research Institute of Pharmacy, University of Groningen,

Antonius Deusinglaan 1, 9713 AV, Groningen, The Netherlands

e-mail: w.j.quax@rug.nl

P. Horvatovich

Department of Analytical Biochemistry, Groningen Research Institute of Pharmacy, University of Groningen, Groningen,

The Netherlands

R. Peters

Proeftuin Ron Peters, Gantel 12, 7891 XAKlazienaveen,

The Netherlands methyl jasmonate on the podophyllotoxin production was determined.

Results More root formation was observed in peat-perlite soil than in sand soil. Furthermore, root formation was higher at $15^{\circ} \mathrm{C}$ than at $25^{\circ} \mathrm{C}$. This resulted in the highest podophyllotoxin production per plant in peat-perlite at $15{ }^{\circ} \mathrm{C}(160 \pm 22 \mathrm{mg} /$ plant d.w.). Furthermore, methyl jasmonate treatment of the leaves increased the podophyllotoxin production in the roots by $21 \%$.

Conclusion We were able to cultivate $P$. hexandrum in a glasshouse in the Netherlands and improve the root formation and podophyllotoxin production. This paves the way for large-scale cultivation of $P$. hexandrum in the temperate latitudes for the production of the pharmaceutical interesting podophyllotoxin.

Keywords Podophyllum hexandrum .

Podophyllotoxin $\cdot$ Etoposide $\cdot$ Soil $\cdot$ Temperature $\cdot$

Methyl jasmonate

\section{Introduction}

The high demand for podophyllotoxin as precursor for the synthesis of important anticancer drugs (etoposide and teniposide) has led to the search for alternative sources (Imbert 1998). The commercially exploited natural sources of podophyllotoxin are Podophyllum hexandrum and Podophyllum peltatum (Guerram et al. 2012). Other podophyllotoxin producing plants in this genus are Podophyllum sikkimensis and Podophyllum pleianthum (Jackson and Dewick 1985; Paul et al. 
2013). The highest concentration of podophyllotoxin was found in $P$. hexandrum roots, which varies between $0.025 \%$ and $9.53 \%$ (d.w.) depending on the geographic location (Purohit et al. 1999; Alam et al. 2009; Kitchlu et al. 2011; Sharma et al. 2012; Liu et al. 2015; Pandey et al. 2015). Podophyllotoxin production is not restricted to the roots as low amounts of podophyllotoxin (0.003$0.229 \%$ d.w.) are also found in P. hexandrum leaves (Pandey et al. 2013). Furthermore, several researchers reported podophyllotoxin production in the leaves of P. peltatum (Bastos et al. 1996; Moraes et al. 2000, 2002; Cushman et al. 2006; Zheljazkov et al. 2011). The most recent population study was by Zheljazkov and coworkers who found up to $2.53 \%$ (d.w.) podophyllotoxin (Zheljazkov et al. 2011). The leaves of $P$. peltatum can be an attractive alternative source for podophyllotoxin due to its renewable properties.

$P$. hexandrum is an endangered species according to the Convention of International Trade in Endangered Species of Wild Fauna and Flora (https://www.cites.org/eng/app/appendices.php\#hash2), because of its excessive harvesting. Therefore, several researchers focused on production of podophyllotoxin by chemical synthesis or in vitro cell cultures. The chemical synthesis is difficult due to the presence of four contiguous chiral centers, and the presence of a base sensitive trans-lactone moiety (Canel et al. 2000). Therefore, at least five chemical synthesis steps are necessary to convert the commercially available bromopiperonal, a building block of the GPR30 receptor antagonist (Dennis et al. 2009), into podophyllotoxin or epipodophyllotoxin (Ting and Maimone 2014). As an alternative, podophyllotoxin production in cell suspension cultures has been explored. This approach, however, provides a low yield with the highest production rate of podophyllotoxin reaching $0.65 \%$ (d.w.) (Petersen and Alfermann 2001; Ionkova et al. 2010). Untill now neither the chemical synthesis nor the in vitro production of podophyllotoxin is economically competitive with the extraction of podophyllotoxin from $P$. hexandrum. Therefore, we focused in this study on improving the cultivation conditions of $P$. hexandrum to ensure a sustainable supply of $P$. hexandrum roots for isolation of podophyllotoxin. Until now, most conservation studies focused on enhancing seed germination or the propagation/transplantation of the plants (Nadeem et al. 2000; Guo et al. 2012). However, no research was done on increasing root formation of mature plants or increasing podophyllotoxin production in vivo. Several researchers reported that the plant morphology and the geographic location, especially the altitude, are important factors for podophyllotoxin production (Purohit et al. 1999; Alam et al. 2009; Kitchlu et al. 2011; Paul et al. 2013; Pandey et al. 2015). Alam and Naik found that high podophyllotoxin production was correlated to low $\mathrm{pH}$, high organic content and high nitrogen levels in the soil (Alam and Naik 2009). Another factor important for the production of podophyllotoxin is temperature as some lignan biosynthesis genes were found to exhibit a higher expression level at $15^{\circ} \mathrm{C}$ rather than at $25^{\circ} \mathrm{C}$ (Kumari et al. 2014). Until now, the influence of soil composition and cultivation temperature on podophyllotoxin production in $P$. hexandrum roots has not been investigated in a glasshouse.

Besides cultivation conditions, hormone induction can be used to increase production of secondary metabolites. Elicitation of medicinal plant species by jasmonates activates transcription factors followed by upregulation of the production of structurally divergent secondary metabolites, such as nicotine and artemisinin (De Geyter et al. 2012). Most elicitation studies have been performed on cell suspension and hairy root cultures (van der Fits 2000; Häkkinen et al. 2004; Baldi and Dixit 2008; Todd et al. 2010; Shoji et al. 2010; Suttipanta et al. 2011). Also the podophyllotoxin production in $P$. hexandrum suspension cultures was increased by seven to eight-fold after stimulation with methyl jasmonate (Bhattacharyya et al. 2012). Furthermore, methyl jasmonate treatment is also effective in vivo, as treatment of Nicotiana attenuata leaves increased nicotine production in the roots (Baldwin 1996). Whether methyl jasmonate can increase the amount of podophyllotoxin in vivo, and whether this effect can be obtained by spraying the leaves, has not been reported up to now.

Our aim was to enhance the root formation and podophyllotoxin production in $P$. hexandrum in a glasshouse in the Netherlands to meet the high demand of podophyllotoxin. The influence of soil, temperature and methyl jasmonate was investigated in a systematic approach. In order to compare the podophyllotoxin production between conditions, a novel quick extraction method was designed. 


\section{Materials and methods}

\section{Experimental design}

P. hexandrum plants were cultivated under various growth conditions (soil, temperature and jasmonate treatment) to investigate root formation and podophyllotoxin production. The temperature study was done with 150 plants; 75 plants cultivated at $15{ }^{\circ} \mathrm{C}$ and 75 plants cultivated at $25^{\circ} \mathrm{C}$. The soil study (sand versus peat-perlite) was performed at both temperatures with 30 plants for each soil type. Sand and peat-perlite were previously described to be successful for $P$. hexandrum, respectively for the germination of seeds and in transplanting of rootlets into soil (Kharkwal et al. 2008; Guo et al. 2012). For statistical analysis, a factorial design was used with three factors: soil, temperature and time. Soil was analyzed at two levels: sand and peat-perlite soil; temperature at two levels: $15^{\circ} \mathrm{C}$ and $25^{\circ} \mathrm{C}$; and time at three levels: 0,20 and 40 days. The podophyllotoxin content was determined per three plants; therefore, plant identifiers were included as additional factor in the podophyllotoxin data analysis.

The methyl jasmonate study was performed with 75 plants, from which 30 plants were treated with methyl jasmonate and 45 plants were treated with water.

\section{Chemicals}

Technical methanol $(98.5 \%(v / v))$ and acetonitrile $(99.9 \%$ $(v / v))$ were purchased from VWR, Fontenay-Sous-Boris, France. Podophyllotoxin $(\geq 98 \%(v / v))$, methyl jasmonate $(95 \%(v / v))$ and ammonium formate $(>97 \%(v / v))$ were purchased from Sigma-Aldrich, St. Louis, USA. Other chemicals were methanol absolute AR $(99.8 \%(v / v)$, Biosolve, Valkenswaard, The Netherlands) and formic acid (98-100\% (v/v), Merck, Darmstadt, Germany), peat (Horticoop, Klazienaveen, The Netherlands) and perlite (Pull Rhenen, Rhenen, The Netherlands).

\section{Plant cultivation}

Two batches of isogenetic $P$. hexandrum plants were obtained from plant breeder Heutinck (Borculo and Gilde, The Netherlands). The first batch contained 150 plants that had been grown for 12 to 24 months in Borculo. The second batch contained 75 plants that had been grown for 24 months in Gilde. All plants arrived in pots with peat soil enriched by addition of calcium and NPK (nitrogen, phosphorous, and potassium) and were stored at $7-8{ }^{\circ} \mathrm{C}$ in the dark to prevent shoot formation. Plants were cultivated in the glasshouse of Proeftuin Ron Peters (Klazienaveen, the Netherlands) in sand soil or peat-perlite soil (Table S1). The peat and perlite were mixed in a ratio 2:1 $(w / w)$. For every condition and time point fifteen plants were randomly harvested.

The soil and temperature study was done with the batch from Borculo (150 plants). The plants cultivated at $15^{\circ} \mathrm{C}$ were grown in March and April of 2015 and the plants cultivated at $25^{\circ} \mathrm{C}$ in May and June 2015. The average temperatures were $15 \pm 2{ }^{\circ} \mathrm{C}$ and $22 \pm 4{ }^{\circ} \mathrm{C}$, respectively, and the average radiation sums were $1158 \pm 450$ joules $/ \mathrm{cm}^{2}$ and $1554 \pm 531$ joules $/ \mathrm{cm}^{2}$ (Table S2). The root biomass and podophyllotoxin content of fifteen plants of each temperature group were analyzed at the beginning. The other plants were harvested after 20 or 40 days of cultivation.

The batch from Gilde (75 plants) was used for the methyl jasmonate experiment from March until April 2015. All plants were first cultivated for 20 days before methyl jasmonate treatment; 15 plants were immediately harvested for baseline control, 30 plants were sprayed with water (control) and 30 plants were sprayed with 51 of $1.5 \mathrm{mM}$ methyl jasmonate. After nine days, fifteen plants in each group were harvested for analysis. The plants in the treatment group were sprayed again for three consecutive days, five liters of $3 \mathrm{mM}$ methyl jasmonate each day. The next day all plants were harvested for analysis.

\section{Plant processing}

Roots were collected from each plant and rinsed with tap water. The roots were dried for $18 \mathrm{~h}$ at $40{ }^{\circ} \mathrm{C}$ (Table S3). Plant roots were pooled per three plants and ground to $1 \mathrm{~mm}$ size with an MF 10 basic grinder of IKA, $3000 \mathrm{rpm}$, and stored at room temperature in closed containers in the dark.

\section{Extraction of podophyllotoxin from plant roots}

The amount of podophyllotoxin in the roots was determined by extraction of podophyllotoxin by two different extraction methods: quick methanol and Soxhlet. 


\section{Quick methanol extraction}

A quick methanol extraction method was designed to process the large number of samples in this study. All extractions were done in triplicate. One gram of plant material was weighed and $10 \mathrm{ml}$ methanol was added. The sample was vortexed for thirty seconds on a Heidolph Reax top, at $2500 \mathrm{rpm}$ (Heidolph, Essex, UK), and incubated in a $65^{\circ} \mathrm{C}$ water bath for ten minutes. The sample was centrifuged at $2400 \mathrm{~g}$ for ten minutes at $4{ }^{\circ} \mathrm{C}$ and the supernatant was transferred to a clean tube. This extraction was repeated five times. The volume of each extraction was separately adjusted in volumetric flasks, $50 \mathrm{ml}$ for the first three extractions and $20 \mathrm{ml}$ for the last three extractions. The podophyllotoxin concentration was determined by HPLC analysis. Samples were stored at $4{ }^{\circ} \mathrm{C}$ before analysis. Podophyllotoxin is stable in the refrigerator at $4{ }^{\circ} \mathrm{C}$ for at least three months and at $25^{\circ}$ in the autosampler of the HPLC for at least $30 \mathrm{~h}$.

\section{Soxhlet extraction}

The Soxhlet method has been previously used for podophyllotoxin extraction (Gupta et al. 2013). Soxhlet extraction was done in a Tecator Soxtec System HT2 that consisted of two 1045 extraction units connected to one 1046 service unit (Gemini, Apeldoorn, The Netherlands). One gram of plant material was weighed and transferred to a cellulose thimble (Fisher Scientific, Pittsburgh, USA). The sample was extracted three times for one hour. The first two extractions were pooled and the volume was adjusted to $100 \mathrm{ml}$ in a volumetric flask. The volume of the third extraction was adjusted to $20 \mathrm{ml}$. The podophyllotoxin concentration was determined by HPLC analysis. Samples were stored at $4{ }^{\circ} \mathrm{C}$ before analysis.

Assessment of podophyllotoxin concentration by HPLC

To determine the amount of podophyllotoxin in the extracted samples, HPLC analysis was performed as previously described by Hendrawati and coworkers with some modifications (Hendrawati et al. 2011). A Shimadzu-VP system (Shimadzu, 's-Hertogenbosch, The Netherlands) was used, consisting of a LC-10AT pump, a SIL-20A auto sampler and a diode array detector SPD-M10A. For analysis a Zorbax Eclipse XDBC18 column (4.6 id. $\times 150$ mm; $5 \mu \mathrm{m}$, Agilent, Santa
Clara, USA) and an Eclipse XDB-C18 guard column containing cartridges ( $4.6 \mathrm{id}$. $\times 12.5 \mathrm{~mm}, 5 \mu \mathrm{m}$, Agilent, Santa Clara, USA) were used. The mobile phase A was [ $\left.\mathrm{H}_{2} \mathrm{O}: \mathrm{ACN}(95: 5)\right]$ and $\mathrm{B}$ [ACN: $\left.\mathrm{H}_{2} \mathrm{O}(95: 5)\right]$, both supplemented with $0.1 \%$ formic acid and $2 \mathrm{mM}$ ammonium formate. The injection volume was $10 \mu \mathrm{l}$ with a flow rate of $1 \mathrm{ml} \mathrm{min}^{-1}$ using a time program of 40 min consisting of $(\mathrm{A}: \mathrm{B}) 10 \mathrm{~min} 70: 30(\mathrm{v} / \mathrm{v})$ isocratic; gradient $8 \mathrm{~min}$ to $50: 50(\mathrm{v} / \mathrm{v})$; gradient $7 \mathrm{~min}$ to $10: 90(\mathrm{v} / \mathrm{v})$; $5 \mathrm{~min}$ 10:90 (v/v) isocratic; gradient $5 \mathrm{~min}$ to $70: 30(\mathrm{v} /$ v) and equilibration of the LC column with $5 \min 70: 30$ $(v / v)$ isocratic elution prior to the next analysis. The column temperature was held constant at $25^{\circ} \mathrm{C}$ and for detection a wavelength of $289 \mathrm{~nm}$ was used. A calibration curve was used to determine the podophyllotoxin concentration $(10-320 \mu \mathrm{g} / \mathrm{ml}$, correlation coefficients $>0.999$ ).

\section{Confirmation of podophyllotoxin by LC-ESI-MS/MS}

The presence of podophyllotoxin in the extracted samples was confirmed by LC-ESI-MS/MS (Fig. S1). The analysis was performed using a Shimadzu LC system, consisting of two LC-20 AD gradient pumps and a SIL20 AC auto sampler. The LC system was coupled to an API 3000 triple quadrupole mass spectrometer (Applied Biosystems/MDS Sciex) via a TurbolonSpray source. Data were collected and analyzed by Analyst 1.5.2 acquisition software (Applied Biosystems/MDS Sciex). The same column, guard column, buffers and gradient program were used as for the HPLC analysis. Samples were diluted 50 times and $20 \mu \mathrm{l}$ was injected. The ionization was performed by electrospray in the positive mode $\left((\mathrm{M}+\mathrm{H})^{+}\right.$and/or $\left(\mathrm{M}+\mathrm{NH}_{4}\right)$ adduct ions $)$. The source temperature was set to $450{ }^{\circ} \mathrm{C}$. The instrument was operated with an ionspray voltage of $5.2 \mathrm{kV}$. Nitrogen was used both for curtain gas and nebulizing gas. Full scan mass spectra were acquired at a scan rate of $1 \mathrm{scan} / 4 \mathrm{~s}$ with a scan range of 100-1300 amu and a step size of $0.1 \mathrm{amu}$.

\section{Statistics}

Statistical analysis was performed with SPSS 23 software and Matlab R2013b. For temperature and soil study, two-way ANOVA was used for significance testing of the root biomass and multiple-way ANOVA with plant as nested factor for the podophyllotoxin content (mg/g or mg/plant). ANOVA analysis assumes normal 
distribution and homoscedasticity of the residuals. The data were $\log _{\mathrm{e}}$ transformed before ANOVA analysis. Outliers were discarded with 5\% cumulative distribution cut-off for the root biomass data and $2.5 \%$ cumulative distribution cut-off for the podophyllotoxin data (twosided). Factors were considered significant for $p$-values $<0.05$. Bonferroni multiple testing correction was performed for post hoc analysis and for the methyl jasmonate study.

\section{Results}

Validation of the quick methanol extraction method for podophyllotoxin extraction

A novel, quick methanol extraction method was applied in this study to process the large number of samples. To validate this method the amount of podophyllotoxin in the roots was determined by the traditional Soxhlet extraction method earlier described by Gupta and coworkers (Gupta et al. 2013). Furthermore, the presence of podophyllotoxin was confirmed by LC-ESI-MS/MS. The podophyllotoxin yield after two rounds of methanol extraction was $16.0 \pm 0.4 \mathrm{mg} / \mathrm{g}$, after three rounds $18.1 \pm 0.6 \mathrm{mg} / \mathrm{g}$ and after six rounds $19.4 \pm 0.5 \mathrm{mg} / \mathrm{g}$ (Table 1). On the contrary, only $18.1 \pm 0.7 \mathrm{mg} / \mathrm{g}$ was extracted by Soxhlet extraction. For the quick methanol extraction method the intraday and interday variation were lower than $4 \%$ (Table 2). As the majority of podophyllotoxin was extracted from $P$. hexandrum roots in the first three fractions, the final extraction protocol included three consecutive extraction rounds. The quick methanol extraction method is able to extract podophyllotoxin from $P$. hexandrum roots in high quantities. Moreover, this method uses less solvent and is quicker, easier and more suitable to extract multiple samples simultaneously than the Soxhlet extraction method.

Influence of soil and temperature on root formation and podophyllotoxin production

Root formation and podophyllotoxin production of $P$. hexandrum roots cultivated in a glasshouse were determined for two soil types and two temperatures. Soil type, temperature and cultivation time have effect on the root formation as shown by two-way ANOVA (Fig. 1a, Table 3). After 20 days of cultivation no increase in
Table 1 Podophyllotoxin extraction by quick methanol and Soxhlet extraction

\begin{tabular}{lll}
\hline Extraction method & Extraction round & PPT $(\mathrm{mg} / \mathrm{g})$ \\
\hline Methanol $(n=4)$ & $1-2$ & $16.0 \pm 0.4$ \\
& 3 & $2.4 \pm 0.1$ \\
& 4 & $0.90 \pm 0.02$ \\
& 5 & $0.35 \pm 0.03$ \\
Soxhlet $(n=3)$ & 6 & $0.15 \pm 0.03$ \\
& $1-2$ & $18.1 \pm 0.6$ \\
& 3 & $\mathrm{ND}$
\end{tabular}

Podophyllotoxin content was determined by HPLC. Values present means \pm standard deviation (d.w.). PPT: podophyllotoxin, ND: not detectable

biomass was observed; therefore, we focused on the effect of soil and temperature after 40 days of cultivation (Fig. 1a, Table 4). Soil has an effect on root biomass production. In peat-perlite soil ( $7 \pm 2 \mathrm{~g}$ d.w.) higher root biomass was observed than in sand soil ( $4 \pm 2 \mathrm{~g} \mathrm{~d}$.w.) for cultivation at $25{ }^{\circ} \mathrm{C}$. No differences were observed at $15^{\circ} \mathrm{C}$. Furthermore, after 80 days of cultivation the average root weight was increased three times more on peat-perlite soil $(13 \pm 2 \mathrm{~g})$ than on sand soil $(3.6 \pm 0.2 \mathrm{~g}$, Fig. 1b). Next, the effect of temperature on root biomass production was determined. At $15^{\circ} \mathrm{C}(8 \pm 1 \mathrm{~g}$ d.w. $)$ more root biomass was observed than at $25^{\circ} \mathrm{C}(4 \pm 2 \mathrm{~g} \mathrm{~d}$.w. ) for cultivation in sand soil. However, this difference was not observed in peat-perlite soil. Increase in root formation in time was only observed for peat-perlite at $15{ }^{\circ} \mathrm{C}(5 \pm 2 \mathrm{~g}$ to $10 \pm 3 \mathrm{~g}$ d.w.).

Besides root formation, the effect of soil and temperature on the podophyllotoxin production was also determined. Soil and temperature had no effect on podophyllotoxin production if normalized for biomass (mg/g d.w.) (Fig. 2a, Table 3). Higher podophyllotoxin production per plant (Fig. 2b, Table 3) was observed for cultivation in peat-perlite $(126 \pm 40 \mathrm{mg} /$ plant d.w. $)$ than

Table 2 Intra-day and inter-day variation in quick methanol extraction

\begin{tabular}{llll}
\hline & & \multicolumn{2}{l}{ Coefficient of variation $(\%)$} \\
\hline & Conc. $(\mu \mathrm{g} / \mathrm{ml})$ & Intra-day & Inter-day \\
Podophyllotoxin & $14.2 \pm 0.6$ & 3.1 & 3.8 \\
\hline $\begin{array}{l}\text { Podophyllotoxin was extracted from five samples on each of the } \\
\text { three analysis days }(n=15) \text {. Podophyllotoxin content was deter- } \\
\text { mined by HPLC }\end{array}$
\end{tabular}


Fig. 1 Influence of soil type and temperature on the root biomass of Podophyllum hexandrum roots. a Root biomass production after 20 days (left) and 40 days (right) was determined. Means are shown by horizontal lines. Podophyllum hexandrum was cultivated in sand soil at $15^{\circ} \mathrm{C}(\bullet)$ or $25^{\circ} \mathrm{C}(\mathbf{\square})$ or in peat-perlite soil at $15{ }^{\circ} \mathrm{C}(\boldsymbol{\Delta})$ or $25{ }^{\circ} \mathrm{C}(\boldsymbol{\nabla})$. Post hoc analysis $p<0.0042 *$ is shown in the figure. $\mathbf{b}$ Visual comparison of $P$. hexandrum roots cultivated for 80 days in sand soil (left, $n=2$ ) and peatperlite (right, $n=3$ )
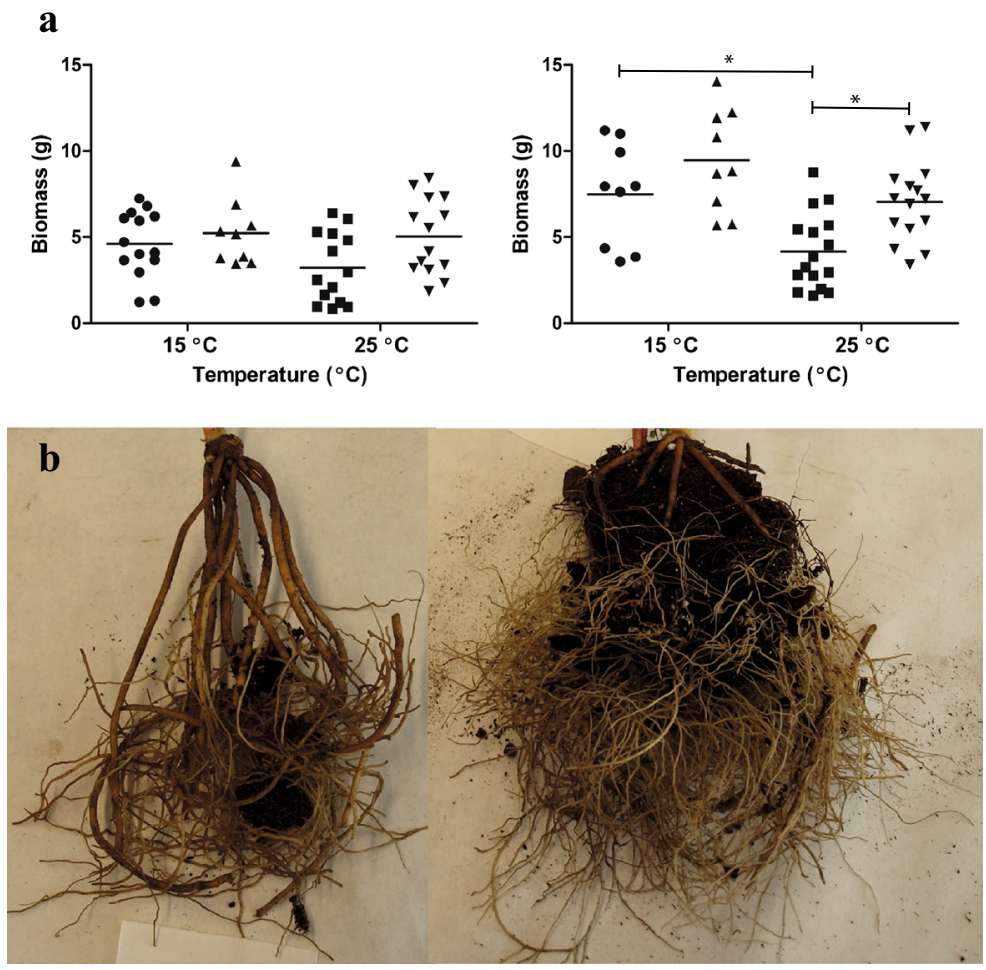

in sand soil $(107 \pm 26 \mathrm{mg} /$ plant d.w.). Cultivation at $15{ }^{\circ} \mathrm{C}(138 \pm 29 \mathrm{mg} /$ plant d.w. $)$ had significantly higher production than at $25^{\circ} \mathrm{C}(72 \pm 25 \mathrm{mg} /$ plant d.w. $)$.
Overall, we can conclude that peat-perlite soil and $15^{\circ} \mathrm{C}$ are the best conditions for root formation and podophyllotoxin production per plant.

Table 3 The influence of cultivation time, temperature and soil type on root biomass and podophyllotoxin production

\begin{tabular}{|c|c|c|c|c|c|}
\hline Cultivation time (days) & Temperature $\left({ }^{\circ} \mathrm{C}\right)$ & Soil type $=$ & Root Biomass (g) & PPT (mg/g) & PPT (mg/plant) \\
\hline \multirow[t]{2}{*}{0} & 15 & Pot & $8 \pm 3$ & $12 \pm 2$ & $66 \pm 12$ \\
\hline & 25 & Pot & $5 \pm 3$ & $15 \pm 2$ & $71 \pm 11$ \\
\hline \multirow[t]{4}{*}{20} & 15 & Sand & $5 \pm 2$ & $12 \pm 2$ & $62 \pm 9$ \\
\hline & & Peat-perlite & $5 \pm 2$ & $13 \pm 4$ & $64 \pm 24$ \\
\hline & 25 & Sand & $3 \pm 2$ & $12 \pm 3$ & $45 \pm 12$ \\
\hline & & Peat-perlite & $5 \pm 2$ & $16 \pm 4$ & $85 \pm 23$ \\
\hline \multirow[t]{4}{*}{40} & 15 & Sand & $8 \pm 1$ & $13 \pm 1$ & $115 \pm 12$ \\
\hline & & Peat-perlite & $10 \pm 3$ & $15 \pm 2$ & $160 \pm 22$ \\
\hline & 25 & Sand & $4 \pm 2$ & $12 \pm 3$ & $56 \pm 16$ \\
\hline & & Peat-perlite & $7 \pm 2$ & $12 \pm 3$ & $92 \pm 17$ \\
\hline \multicolumn{3}{|l|}{ Soil } & $* * *$ & $\mathrm{~ns}$ & $* * *$ \\
\hline \multicolumn{3}{|l|}{ Temperature } & $* * *$ & ns & $* *$ \\
\hline \multicolumn{3}{|l|}{ Time } & $* * *$ & ns & $* * *$ \\
\hline \multicolumn{3}{|c|}{ Soil $\mathrm{x}$ Temperature $\mathrm{x}$ Time } & ns & $* * *$ & $* * *$ \\
\hline
\end{tabular}

Values present means \pm standard deviation (d.w.) and $* *$ and $* * *$ denote significance at 0.01 and 0.001 probability level, respectively. ns: non-significant, PPT: podophyllotoxin 
Table 4 Bonferroni multiple testing correction for root biomass and podophyllotoxin production

\begin{tabular}{|c|c|c|c|}
\hline \multicolumn{2}{|l|}{ Factor 1 vs. Factor 2} & \multirow{2}{*}{$\frac{\text { Root biomass }(\mathrm{g})}{0.0113}$} & \multirow{2}{*}{$\begin{array}{l}\text { Podophyllotoxin (mg/plant) } \\
0.2990\end{array}$} \\
\hline$t=0,15^{\circ} \mathrm{C}$ & $t=0,25^{\circ} \mathrm{C}$ & & \\
\hline$t=20,15^{\circ} \mathrm{C}$, Sand & $t=20,15^{\circ} \mathrm{C}$, Peat-perlite & 0.3163 & 0.7632 \\
\hline$t=20,25^{\circ} \mathrm{C}$, Sand & $t=20,25^{\circ} \mathrm{C}$, Peat-perlite & 0.0236 & $<0.0001 * *$ \\
\hline$t=20,15^{\circ} \mathrm{C}$, Sand & $t=20,25^{\circ} \mathrm{C}$, Sand & 0.0736 & $0.0007 *$ \\
\hline$t=20,15^{\circ} \mathrm{C}$, Peat-perlite & $t=20,25^{\circ} \mathrm{C}$, Peat-perlite, & 0.634 & 0.0643 \\
\hline$t=40,15^{\circ} \mathrm{C}$, Sand & $t=40,15^{\circ} \mathrm{C}$, Peat-perlite & 0.1173 & $<0.0001 * *$ \\
\hline$t=40,25^{\circ} \mathrm{C}$, Sand & $t=40,25^{\circ} \mathrm{C}$, Peat-perlite & $0.0011 *$ & $<0.0001 * *$ \\
\hline$t=40,15^{\circ} \mathrm{C}$, Sand & $t=40,25^{\circ} \mathrm{C}$, Sand & $0.0015 *$ & $<0.0001 * *$ \\
\hline$t=40,15^{\circ} \mathrm{C}$, Peat-perlite & $t=40,25^{\circ} \mathrm{C}$, Peat-perlite, & 0.0487 & $<0.0001 * *$ \\
\hline$t=20,15^{\circ} \mathrm{C}$, Sand & $t=40,15^{\circ} \mathrm{C}$, Sand & 0.0112 & $<0.0001 * *$ \\
\hline$t=20,15^{\circ} \mathrm{C}$, Peat-perlite & $t=40,15^{\circ} \mathrm{C}$, Peat-perlite & $0.0018 *$ & $<0.0001 * *$ \\
\hline$t=20,25^{\circ} \mathrm{C}$, Sand & $t=40,25^{\circ} \mathrm{C}$, Sand & 0.16 & 0.0363 \\
\hline$t=20,25^{\circ} \mathrm{C}$, Peat-perlite & $t=40,25^{\circ} \mathrm{C}$, Peat-perlite & 0.0251 & 0.2916 \\
\hline
\end{tabular}

$*$ and $* *$ denote significance at 0.0038 and 0.0001 probability level, respectively

Influence of methyl jasmonate treatment on the production of podophyllotoxin

In literature, enhancement of certain secondary metabolites was obtained through chemical induction by methyl jasmonate treatment. Therefore, we studied whether spraying of methyl jasmonate on $P$. hexandrum leaves can increase the amount of podophyllotoxin in the roots. A single methyl jasmonate treatment (1.5 mM solution) was insufficient to enhance the podophyllotoxin production after 9 days (Fig. 3a, pvalue 0.39 ). Increasing the dosage to 2 -fold ( $3 \mathrm{mM}$ solution) and treatment on three consecutive days resulted in $21 \%$ higher podophyllotoxin production (14 $\pm 3 \mathrm{mg} / \mathrm{g}$ to $17 \pm 3 \mathrm{mg} / \mathrm{g}$ d.w., Fig. $3 \mathrm{~b}$, p-value 0.01). In conclusion, methyl jasmonate treatment on the leaves can enhance the podophyllotoxin production in the roots of $P$. hexandrum.
Fig. 2 Influence of soil type and temperature on the podophyllotoxin production in Podophyllum hexandrum roots. a Biomass normalized podophyllotoxin production after 20 days (left) and 40 days (right), b Podophyllotoxin production per plant after 20 days (left) and 40 days (right). Means are shown by horizontal lines. $P$. hexandrum was cultivated in sand soil at $15^{\circ} \mathrm{C}(\bullet)$ or $25^{\circ} \mathrm{C}(\boldsymbol{\bullet})$ or in peatperlite soil at $15^{\circ} \mathrm{C}(\boldsymbol{\Delta})$ or $25^{\circ} \mathrm{C}$ $(\boldsymbol{\nabla})$. Post hoc analysis: $p$-value $<0.0042(*)$ and $p$-value $<0.0001$ $(* *)$ are shown in the figure
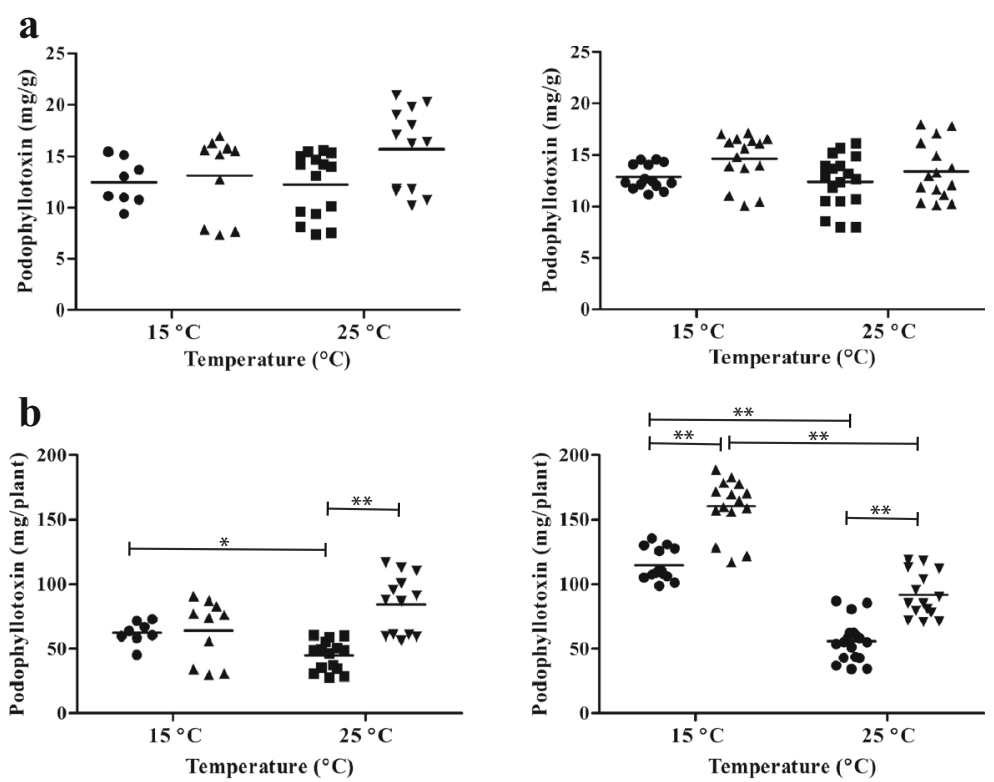

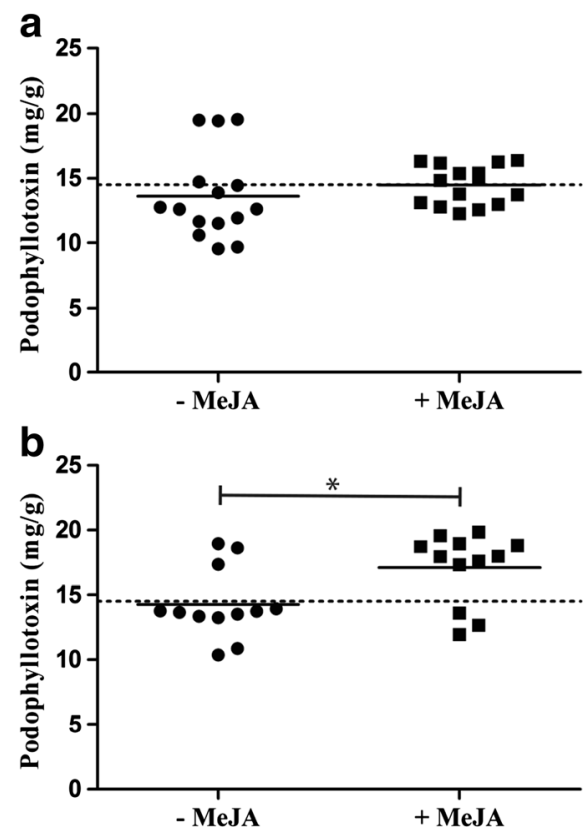

Fig. 3 Influence of methyl jasmonate on the amount of podophyllotoxin in Podophyllum hexandrum roots. a Single methyl jasmonate treatment (1.5 mM, harvested after 9 days), $\mathbf{b}$ additional treatment on three consecutive days $(3 \mathrm{mM}$, harvest on the fourth day), Means are shown by horizontal lines and the baseline by the dotted line. Post hoc analysis $p$-value $<0.025(*)$ is shown in the figure. Treatment symbols: $\bullet=$ water; $\boldsymbol{\square}=$ methyl jasmonate

\section{Discussion}

Podophyllotoxin is the precursor for high value anticancer drugs, such as etoposide and teniposide. The scarcity of the podophyllotoxin source, $P$. hexandrum, in nature has led to the need of controlled cultivation. Furthermore, increase of podophyllotoxin production per plant will reduce the number of plants necessary for podophyllotoxin extraction. Therefore, the influences of soil, temperature and methyl jasmonate treatment on the root biomass formation and podophyllotoxin production were determined by cultivation of $P$. hexandrum in a glasshouse in the Netherlands. First, a novel quick methanol extraction method was designed for the extraction of podophyllotoxin from $P$. hexandrum roots in order to process the large number of samples. The extraction yield of this method is comparable to Soxhlet. However, the benefit of the quick methanol extraction method is a shorter and easier extraction procedure and usage of less organic solvent.

Environmental conditions like soil composition and temperature are important parameters for $P$. hexandrum cultivation and podophyllotoxin production (Alam et al.
2009; Kumari et al. 2014). Therefore, root biomass and podophyllotoxin production were determined for two soil types (sand and peat-perlite) and two temperatures $\left(15^{\circ} \mathrm{C}\right.$ and $\left.25^{\circ} \mathrm{C}\right)$. As expected controlling soil aeration and water drainage by perlite in combination with the properties of peat to absorb moisture and nutrients resulted in the highest root biomass per plant. Lower temperatures are favorable for root formation as the root biomass production was higher at $15^{\circ} \mathrm{C}$ than at $25^{\circ} \mathrm{C}$. However, the podophyllotoxin production normalized to the root biomass was neither effected by various soils nor temperatures. This is in contrast to the report of Kumari and coworkers who observed a decreasing trend of podophyllotoxin accumulation at $25^{\circ} \mathrm{C}$ in growth chambers under controlled artificial light (Kumari et al. 2014). This contrast in findings can be explained by the importance of sunlight duration on the production of podophyllotoxin (Cushman et al. 2005; Liu et al. 2015). Kumari's study was performed under constant artificial light and our study was done in natural daylight, which varied at $15{ }^{\circ} \mathrm{C}\left(1158 \pm 450\right.$ joules $\left./ \mathrm{cm}^{2}\right)$ and $25{ }^{\circ} \mathrm{C}$ $\left(1554 \pm 531\right.$ joules $\left./ \mathrm{cm}^{2}\right)$.

Methyl jasmonate is known to upregulate various transcription factors, such as R2R3 Myb. This transcription factor upregulates the rate-limiting steps in the phenylpropanoid biosynthesis, which is followed by the lignan pathway were podophyllotoxin is produced (Gális et al. 2006). Treatment of the leaves of the $P$. hexandrum plant with methyl jasmonate indeed increased the podophyllotoxin production in the roots by $21 \%$. This observation is in line with the findings of Bhattacharyya in cell cultures of $P$. hexandrum (Bhattacharyya et al. 2012). As previously observed by Baldwin, treatment of the leaves triggers the secondary metabolite production (nicotine) in the roots (Baldwin 1996). In our study, the podophyllotoxin production was increased from 1.4 to $1.7 \%$ (d.w.). These percentages are also observed for $P$. hexandrum in the natural habitat (Purohit et al. 1999; Alam et al. 2009; Kitchlu et al. 2011; Sharma et al. 2012; Liu et al. 2015; Pandey et al. 2015). Our study describes the ability to improve the root formation and the podophyllotoxin production in isogenic $P$. hexandrum cultivated in a glasshouse in the Netherlands. The seasonal variations in temperature in the Netherlands are optimal for cultivation of $P$. hexandrum in glasshouses without extra heating expenses. The advantage of growing in a glasshouse is the ability to control cultivation conditions, such as light and water. Furthermore, pest control can be applied in order to create stable and robust 
conditions for growth of this medicinal plant. This study paves the way for large-scale cultivation of $P$. hexandrum in the temperate latitudes for the production of the pharmaceutically important podophyllotoxin.

Acknowledgements We thank Filipa Bico for her support in the glasshouse. We thank C.M. Jeronimus-stratingh of the Mass Spectrometry Core Facility of the University of Groningen for the LC-ESI-MS/MS analysis. This research was financially supported by EU regional funding: the PhytoSana project in the INTERREG IV A Deutschland-Nederland program (34- INTERREG IVA I-101 = 193 PhytoSana).

Open Access This article is distributed under the terms of the Creative Commons Attribution 4.0 International License (http:// creativecommons.org/licenses/by/4.0/), which permits unrestricted use, distribution, and reproduction in any medium, provided you give appropriate credit to the original author(s) and the source, provide a link to the Creative Commons license, and indicate if changes were made.

\section{References}

Alam MA, Gulati P, Gulati AK et al (2009) Assessment of genetic diversity among Podophyllum hexandrum genotypes of the north-western Himalayan region for podophyllotoxin production. Indian J Biotechnol 8:391-399

Alam MA, Naik PK (2009) Impact of soil nutrients and environmental factors on podophyllotoxin content among 28 Podophyllum hexandrum populations of northwestern Himalayan region using linear and nonlinear approaches. Commun Soil Sci Plant Anal doi:10.1080 /00103620903111368

Baldi A, Dixit VK (2008) Yield enhancement strategies for artemisinin production by suspension cultures of Artemisia annua. Bioresour Technol 99:4609-4614. doi:10.1016/j. biortech.2007.06.061

Baldwin IT (1996) Methyl jasmonate-induced nicotine production in Nicotiana attenuata: inducing defenses in the field without wounding. Entomol Exp Appl 80:213-220. doi:10.1111 /j.1570-7458.1996.tb00921.x

Bastos JK, Burandt CL, Nanayakkara NPD et al (1996) Quantitation of aryltetralin lignans in plant parts and among different populations of Podophyllum peltatum by reversedphase high-performance liquid chromatography. J Nat Prod 59:406-408. doi:10.1021/np960155d

Bhattacharyya D, Sinha R, Ghanta S et al (2012) Proteins differentially expressed in elicited cell suspension culture of Podophyllum hexandrum with enhanced podophyllotoxin content. Proteome Sci 10:34. doi:10.1186/1477-5956-10-34

Canel C, Moraes RM, Dayan FE, Ferreira D (2000) Podophyllotoxin. Phytochemistry 54:115-120. doi:10.1016 /S0031-9422(00)00094-7

Cushman KE, Maqbool M, Lata H et al (2005) Podophyllotoxin content and yield of American mayapple leaves in sun and shade. Hortscience 40:60-63
Cushman KE, Moraes RM, Gerard PD et al (2006) Frequency and timing of leaf removal affect growth and podophyllotoxin content of Podophyllum peltatum in full sun. Planta Med 72: 824-829. doi:10.1055/s-2006-946675

De Geyter N, Gholami A, Goormachtig S, Goossens A (2012) Transcriptional machineries in jasmonate-elicited plant secondary metabolism. Trends Plant Sci 17:349-359. doi:10.1016/j. tplants.2012.03.001

Dennis MK, Burai R, Ramesh C et al (2009) In vivo effects of a GPR30 antagonist. Nat Chem Biol 5:421-427. doi:10.1038 /nchembio. 168

Gális I, Simek P, Narisawa T et al (2006) A novel R2R3 MYB transcription factor NtMYBJS1 is a methyl jasmonatedependent regulator of phenylpropanoid-conjugate biosynthesis in tobacco. Plant J 46:573-592. doi:10.1111/j.1365313X.2006.02719.x

Guerram M, Jiang Z-Z, Zhang L-Y (2012) Podophyllotoxin, a medicinal agent of plant origin: past, present and future. Chin J Nat Med 10:161-169. doi:10.3724/SP.J.1009.2012.00161

Guo Q, Zhou J, Wang Z, Yang H (2012) In vitro rooting of Podophyllum hexandrum and transplanting technique. Engineering 4:142-145. doi:10.4236/eng.2012.410B037

Gupta DK, Verma MK, Lal S et al (2013) Extraction studies of Podophyllum hexandrum using conventional and nonconventional methods by HPLC-UV-DAD. J Liq Chromatogr Relat Technol 37:259-273. doi:10.1080/10826076.2012.745134

Häkkinen ST, Rischer H, Laakso I et al (2004) Anatalline and other methyl jasmonate-inducible nicotine alkaloids from Nicotiana tabacum cv. By-2 cell cultures. Planta Med 70: 936-941. doi:10.1055/s-2004-832620

Hendrawati O, Woerdenbag HJ, Hille J et al (2011) Seasonal variations in the deoxypodophyllotoxin content and yield of Anthriscus sylvestris L. (Hoffm.) grown in the field and under controlled conditions. J Agric Food Chem 59:8132-8139. doi:10.1021/jf200177q

Imbert TF (1998) Discovery of podophyllotoxins. Biochimie 80: 207-222. doi:10.1016/S0300-9084(98)80004-7

Ionkova I, Antonova I, Momekov G, Fuss E (2010) Production of podophyllotoxin in Linum Linearifolium in vitro cultures. Pharmacogn Mag 6:180-185. doi:10.4103/0973-1296.66932

Jackson DE, Dewick PM (1985) Tumour-inhibitory aryltetralin lignans from Podophyllum Pleianthum. Phytochemistry 24: 2407-2409. doi:10.1016/S0031-9422(00)83052-6

Kharkwal AC, Kushwaha R, Prakash O et al (2008) An efficient method of propagation of Podophyllum hexandrum: an endangered medicinal plant of the western Himalayas under ex situ conditions. J Nat Med 62:211-216. doi:10.1007/s11418007-0217-9

Kitchlu S, Ram G, Koul S et al (2011) Podophyllum lignans array of Podophyllum hexandrum Royle populations from semidesert alpine region of Zanskar valley in Himalayas. Ind Crop Prod 33:584-587. doi:10.1016/j.indcrop.2010.12.010

Kumari A, Singh HR, Jha A et al (2014) Transcriptome sequencing of rhizome tissue of Sinopodophyllum hexandrum at two temperatures. BMC Genomics 15:871. doi:10.1186/14712164-15-871

Liu W, Liu J, Yin D, Zhao X (2015) Influence of ecological factors on the production of active substances in the anti-cancer plant Sinopodophyllum hexandrum (Royle) T.S. Ying. PLoS one 10:e0122981. doi:10.1371/journal.pone.0122981 
Moraes RM, Bedir E, Barrett H et al (2002) Evaluation of Podophyllum peltatum accessions for podophyllotoxin production. Planta Med 68:341-344. doi:10.1055/s-2002-26740

Moraes RM, Burandt C, Ganzera M et al (2000) The American mayapple revisited-Podophyllum peltatum - still a potential cash crop? Econ Bot 54:471-476. doi:10.1007/BF02866546

Nadeem M, Palni LMS, Purohit AN et al (2000) Propagation and conservation of Podophyllum hexandrum Royle: an important medicinal herb. Biol Conserv 92:121-129. doi:10.1016 /s0006-3207(99)00059-2

Pandey H, Kumar A, Palni LMS, Nandi SK (2015) Podophyllotoxin content in rhizome and root samples of Podophyllum hexandrum Royle populations from Indian Himalayan region. J Med Plant Res 9:320-325. doi:10.5897/JMPR2014.5627x

Pandey HK, Nandi SK, Palni LMS (2013) Podophyllotoxin content in leaves and stems of Podophyllum hexandrum Royle from Indian Himalayan region. J Med Plant Res 7:32373241. doi:10.5897/JMPR2013.4491

Paul S, Nandi SK, Palni LMS (2013) Assessment of genetic diversity and interspecific relationships among three species of Podophyllum using AFLP markers and podophyllotoxin content. Plant Syst Evol 299:1879-1887. doi:10.1007 /s00606-013-0844-4

Petersen M, Alfermann W (2001) The production of cytotoxic lignans by plant cell cultures. Appl Microbiol Biotechnol 55: 135-142. doi:10.1007/s002530000510

Purohit MC, Bahuguna R, Maithani UC et al (1999) Variation in podophylloresin and podophyllotoxin contents in different populations of Podophyllum hexandrum. Curr Sci 77:10781079

Sharma TR, Singh BM, Sharma NR, Chauhan RS (2012) Identification of high podophyllotoxin producing biotypes of Podophyllum hexandrum royle from north-western Himalaya. J Plant Biochem Biotechnol 9:49-51. doi:10.1007 /BF03263084

Shoji T, Kajikawa M, Hashimoto T (2010) Clustered transcription factor genes regulate nicotine biosynthesis in tobacco. Plant Cell 22:3390-3409. doi:10.1105/tpc.110.078543

Suttipanta N, Pattanaik S, Kulshrestha M et al (2011) The transcription factor CrWRKY1 positively regulates the terpenoid indole alkaloid biosynthesis in Catharanthus roseus. Plant Physiol 157:2081-2093. doi:10.1104/pp.111.181834

Ting CP, Maimone TJ (2014) C-H bond arylation in the synthesis of aryltetralin lignans: a short total synthesis of podophyllotoxin. Angew Chem Int Ed Eng 53:3115-3119. doi:10.1002 /anie. 201311112

Todd AT, Liu E, Polvi SL et al (2010) A functional genomics screen identifies diverse transcription factors that regulate alkaloid biosynthesis in Nicotiana Benthamiana. Plant J 62: 589-600. doi:10.1111/j.1365-313X.2010.04186.x

van der Fits L (2000) ORCA3, a jasmonate-responsive transcriptional regulator of plant primary and secondary metabolism. Science. 289:295-Scie297. doi:10.1126/science.289.5477.295

Zheljazkov VD, Cantrell CL, Astatkie T (2011) Variation in podophyllotoxin concentration in leaves and rhizomes of American mayapple (Podophyllum peltatum L.) Ind Crop Prod 33:633-637. doi:10.1016/j.indcrop.2010.12.025 